\title{
LOS FUNDAMENTOS ARCANOS DE LA CREACIÓN POÉTICA. LA TESIS DE LEÓN HEBREO SOBRE EL VERSO Y EL MITO
}

\author{
Diego Pintado
}

\section{(c)}

Esta obra está bajo una licencia Creative Commons 



\title{
LOS FUNDAMENTOS ARCANOS DE LA CREACIÓN POÉTICA. LA TESIS DE LEÓN HEBREO SOBRE EL VERSO Y EL MITO
}

\author{
ARCANE FUNDAMENTS OF POETIC CREATION. LEÓN HEBREO'S \\ THESIS ON VERSE AND MYTH
}

\author{
Diego Pintado
}

\begin{abstract}
RESUMEN
Este estudio se concentrará en unos pasajes de los Diálogos de amor de León Hebreo en los que se plasma concisamente toda una teoría de la creación poética: sus elementos estructurales, sus sentidos, su finalidad última y sus fundamentos constitutivos y originarios. Se intentará analizar y desarrollar las tesis y premisas de los pasajes citados: la codificación de secretos y distintos niveles de lectura en una obra artística, así como una detallada caracterización de los sentidos y alegorías presentes en la creación poética clásica y arcaica, y asimismo la razón de ser del verso, de la métrica, de las fábulas y de los mitos. A su vez, se harán comentarios y observaciones sobre las reflexiones que hace Filón, el personaje eminente del diálogo, acerca de la postura tomada por Platón y Aristóteles frente al problema del ocultamiento y la difusión de las ciencias y los conocimientos más sagrados.

Palabras clave: simbología, teoría literaria, filosofía del arte, lenguaje alegórico, hermenéutica.
\end{abstract}

\begin{abstract}
This study will focus on some sections of Dialogs of Love, by León Hebreo, in which theory a poetic creation is apparent: constitutive and structural elements, meanings, ultimate purposes and fundaments of origin. An analysis will be done of the meanings and premises of the cited passages: the codification of secrets and different levels of reading in an artistic work, as well as detailed characterization of the meanings and allegories present in the classic and archaic poetic creation, in addition to the justification for the existence of verse, meter, fables and myths. Also, there will be comments and observations on Philo's reflections, an eminent character in this dialogue, in regards to Plato's and Aristotle's positions on the secrecy and diffusion of the sciences and the most sacred of knowledge.
\end{abstract}

Key words: symbolism, literary theory, philosophy of art, allegorical language, hermeneutics.

M. Diego Pintado. Estudiante de Filosofía de la Universidad del Salvador. Argentina. Correo electrónico: nulliusinverba@outlook.com

Recepción: 25- 05- 2016

Aceptación: 18- 08- 2016 


\section{Introducción}

León Hebreo, o Isaac ben Yehudá de Abravanel, es un personaje en nuestros días poco conocido y olvidado. Sus obras no son fáciles de conseguir, y a la última traducción al castellano de los Diálogos de amor sólo pude acceder en biblioteca pública donde felizmente se conserva un ejemplar. Pero no creemos que gocen de mejor suerte otros filósofos y personajes del Renacimiento; de hecho, en muchas universidades de Filosofía esta etapa, estos siglos, tan fecundos, tan valiosos y tan importantes para la historia espiritual, científica, religiosa, filosófica y creativa de Occidente, se pasa por alto, se la omite, está ausente y no es nada más que elipsis entre la filosofía medieval tardía y la filosofía cartesiana.

Los Diálogos de amor es una de las grandes obras filosóficas y literarias renacentistas. Llega a ser traducida por el Inca Garcilaso, lo cual revelaría la importancia que esta obra tuvo inclusive en América por aquellos siglos. Se trata de tres diálogos entre Filón y Sofía, en torno a una cuestión tan cara a los sabios del Renacimiento: el amor. La obra nos sitúa en un mundo en el que Platón y Aristóteles son, además de sabios, maestros del saber esotérico, y en que Moisés revela dotes de filósofo aristotélico y destrezas en magia caldea y pitagórica, en el que la Biblia es citada con la misma autoridad que Virgilio, y el Nombre de Dios es evocado junto con el de Venus o Mercurio.

León Hebreo, judío neoplátonico y de espíritu profundamente renacentista, debió sentirse identificado con Filón de Alejandría, judío platónico y helenizado. ¿Pero a quién están dirigidos estos diálogos? ¿a los judíos helenizados y latinizados para atraerlos al judaísmo a través de Filón? ¿a un proyecto ecumenista con fuente en el humanismo hermético y latino? ¿a los no-judíos descristianizados, que habían vuelto a las antiguas raíces religiosas grecorromanas de la mano de Platón, de Aristóteles y del hermetismo y de obras como el Dialogo sopra l'amore de Ficino, pero sin embargo sensibles a los secretos de la cábala, para reaproximarlos así de alguna manera a Israel? ¿estamos ante una obra con las mismas motivaciones iconoclastas de De natura deorum de Cicerón, que en lugar de hacer desaparecer el politeísmo valiéndose de la crítica racionalista, León Hebreo opta por la estrategia de reducir monoteizantemente el panteón politeísta a meros personajes alegóricos de ficciones poéticas? ¿o acaso simplemente están dirigidos los Diálogos, en perfecta concordia y hermosa con las más sublimes aspiraciones de su tiempo: a la humanitas?

Los Diálogos de amor es una obra que transita los grandes temas latentes en las profundidades del alma humana: los secretos del Cielo y de la Tierra, los misterios de la ciencia astrológica, los orígenes de los mundos inferiores, el desciframiento de los enigmas, y por supuesto las preguntas perennes, como qué es el alma, qué es el amor, qué es el deseo, qué es el hombre, qué es la sabiduría... y la cuestión que no podía estar ausente, en la que enfocaremos este brevísimo estudio, a saber, su concepto de la creación artística: la poesía, el verso, el mito.

Estudiar estos pasajes de León Hebreo asimismo nos brinda la excusa para adentrarnos en una cuestión tan inadvertida y olvidada como es la dimensión secreta y arcana en la concepción artística de todos los tiempos. Carlos Alberto Moreyra, a quien le debemos la no tan inadvertida pero sin dudas olvidada obra La Contrarreforma jesuítica y el gran arte críptico, ${ }^{1}$ cita una frase de Baltazar Gracián en su epígrafe, pasaje que también cita Sebastian Neumeister ${ }^{2}$ en su artículo abocado a estos mismos temas,

Abrió los ojos la Verdad, dio desde entonces en andar con artificio, usa de las invenciones, introdúcese por rodeos, pinta lejos lo que está muy cerca. Habla de lo presente en lo pasado... apunta a uno para dar en otro... 


\title{
2. El arte como arcanización del saber
}

\author{
Mos enim erat veterum theologorum sacra ipsorum puraque arcana, \\ ne a prophanis et impuris polluerentur, figurarum umbraculis tegere. \\ ("Era una costumbre de los teólogos antiguos ocultar los secretos \\ más puros y sagrados en las sombras atrás de las imágenes, para evitar \\ que fueran contaminadas por hombres impuros y profanos.")
}

Esta frase de Marsilio Ficino, traducida por nosotros, es citada por Andrés Soria Olmedo (1986) en el estudio preliminar con el que se presenta a los Diálogos de amor en la edición que utilizaremos cotejándola con el texto original. ${ }^{3}$ Puede decirse que en ella encontramos cifrado un caso perfectamente emblemático de arcanización: no se trata del mero ocultamiento de los secretos más puros y sagrados, sino de su recubrimiento en la oculta y sombría interioridad de las figuras, de los símbolos, de las imágenes y de las representaciones. Se trataría de la codificación críptica de altos secretos - donde están previstos varios niveles de decodificación hermenéutica- en figuras pictóricas, musicales, arquitectónicas, teatrales, narrativas o poéticas que sin embargo tienen sentido por sí mismas, prescindiendo de toda clave interpretativa, y a simple vista casi nadie sospecha que pudiese estar latente, oculto y codificado ningún secreto, ningún mensaje y ninguna revelación. La palabra umbraculum que utiliza Ficino viene a querer decir: mampara o pantalla, esto es, una forma exterior bajo la cual se ocultan conocimientos o doctrinas que solamente puede descifrar el iniciado - o los que han visto, o los que han oído.

El concepto de arcanización es inclusive más complejo, pero es importante explicarlo mejor y comprenderlo bien. La primera vez que me encontré con este término fue en un libro de misticismo judío de Moshe Idel, ${ }^{4}$ en el que se explayaba en trazar una necesaria e indispensable distinción entre el concepto de "misterio" y el de "secreto" - y "arcanización". Observa que, como pensaba Aristóteles, el iniciado en los misterios atraviesa más bien una vivencia o padecimiento transformador, una revelación experiencial, antes que la revelación de una enseñanza. ${ }^{5}$ Moshe Idel - que daría la impresión de estar pensando en el concepto hebreo de sod (secreto) para distinguirlo del mysterium cristiano - lo que busca es caracterizar en términos nítidos y discernibles al iniciado cabalístico, que, a diferencia del iniciado mistérico, lo que recibe es, pudiéramos decir, una revelación hermenéutica, la llave de acceso a las cosas ocultas, un código secreto descifrado - y no una visión mística o una experiencia o una unción sacramental.

Pero el concepto de arcanización de Moshe Idel no es el que nos interesa aquí, si bien aludimos a él como una forma de presentar un concepto de suma utilidad para nuestro brevísimo estudio, pero que sin embargo es desconocido y muchas personas ni siquiera han oído el término hasta hoy. Moshe Idel se concentra en la idea de la arcanización de los textos sagrados: la Biblia, por ejemplo, concebida como una estructura sofisticada de secretos codificados alegórica, anagógica, astrológica y numerológicamente, y en distintos niveles de lectura y claves interpretativas. El concepto de arcanización del que nos ocuparemos es el que presentaremos a continuación a través de las concepciones de la creación poética que encontramos en los Diálogos de amor, que no es muy distante del que expone Idel, y que resumiremos así: es la existencia cifrada de secretos en una creación artística, que generalmente prevé y admite no uno sino varios niveles de decodificación.

Hay un aspecto de la arcanización que no está contemplado - creemos que no está contemplado - en León Hebreo pero que sí es destacado por Moshe Idel incluso por momentos como si fuera el único de los aspectos: es el proceso de introducir secretos o interpretaciones 
secretas en el texto canónico. Esto quiere decir: ni más ni menos que lo que se conoce con la palabra "eiségesis". Es así, eisegéticamente - permítasenos la expresión- como Scholem pareciera asumir al Zóhar:

\begin{abstract}
Debo recordar que el Zóhar, más que desarrollar una idea, la aplica en una homilía, y hay que decir que el autor es realmente un genio del pensamiento homilético. En sus manos, los versículos más simples de las Escrituras adquieren un sentido totalmente inesperado. Como dijo David Neumark, ese agudo historiador de la filosofía judía, ¡hasta el lector crítico se pregunta a veces, lleno de dudas, si la verdadera interpretación de ciertos pasajes de la Torá no se encontrará aquí y no en otros textos! El autor se pierde a menudo en alegorizaciones místicas y no es raro que se vuelva abstruso, pero una y otra vez se nos revela una profundidad oculta y a veces aterradora, y nos hallamos frente a una intuición tan real como profunda. Su estilo, en otras ocasiones tortuoso, se ilumina con una magnífica claridad expresiva, con un símbolo profundo de ese mundo en cuyas regiones ocultas penetró tan a fondo su mente. ${ }^{6}$ (Scholem, 1993, pp. 135-136)
\end{abstract}

León Hebreo se limita, en cambio, a una concepción exegética de la arcanización, mientras que Moshe Idel describe más bien una concepción eisegética. Ésta última parecería quizás coincidir con un espíritu oracular y teúrgico muy propio de los círculos cabalísticos, mientras que León Hebreo parece estar describiendo a una tradición en la que se cifraba en los textos poéticos una condensación de conocimientos científicos, doctrinales, teológicos, sapienciales, astrológicos, metafísicos, alegóricos y filosóficos. Para León Hebreo, la creación poética arcaica contendría un corpus de saberes y enseñanzas secretas de manera críptica y cifrada, mientras para Moshe Idel, en sus estudios de cábala, el texto canónico arcanizado sería como el prodigioso báculo de Moisés revivido y actualizado por diversas y continuas eiségesis de inspiración profética.

Importante es aclarar, a grandes rasgos, qué es lo que entiende León Hebreo por creación poética, o sea, por poesía: lo que entiende es la composición de obras en verso, obedeciendo una estructura métrica, y en la que se narran grandes mitos e historias, como epopeyas o tragedias. Nada tiene que ver su concepción de la poesía con la nuestra, que llamamos así a un libro con sonetos, o con verso libre, o con una miscelánea de poemas breves, de pocos versos, o descriptivos o románticos. Nuestra noción de poesía, la idea vigente entre nosotros, es comparativamente pobre, variada, emotiva, y es, muchas veces, más una proyección de sentimientos que la ardua e inspirada ingeniería creativa de las composiciones más ambiciosas y trascendentales.

Próximos a la concepción originaria de lo poético pudieron estarlo Dante, Shakespeare o Calderón, pero ni siquiera Borges ni Huidobro se han acercado a esta idea de la creación poética que nos describe León Hebreo; recordemos lo que el poeta chileno dice en su Manifiesto,

El reinado de la literatura terminó. El siglo veinte verá nacer el reinado de la poesía en el verdadero sentido de la palabra, es decir, en el de creación, como la llamaron los griegos, aunque jamás lograron realizar su definición. (Huidobro, 1989, p. 306)

Y más adelante, con hermosura, y no sin ambiciones proféticas, propone,

Si el hombre ha sometido para sí a los tres reinos de la naturaleza, el reino mineral, el vegetal y el animal, ¿por qué razón no podrá agregar a los reinos del universo su propio reino, el reino de sus creaciones? (Huidobro, 1989, p. 307)

Pero la poesía para Huidobro sigue siendo la poesía estética y romántica, la poesía del individuo y sus expresiones, del sujeto y el mundo y la naturaleza... La idea de creación poética 
de Huidobro, que hemos citado porque es paradigmática al respecto, es propiamente profana en el contexto de este estudio. Nadie pretenda rebajar la grandeza que podemos hallar en estos poetas, pero de ninguna manera estamos ni próximos al espíritu de la creación poética arcaico, sagrado y tradicional, y que es en el que está pensando León Hebreo cuando nos explica sus fundamentos arcanos.

\section{Sentidos (sensi) y alegorías (allegorici): niveles de interpretación y decodificación}

A partir de ahora presentaremos al autor en sus propias palabras, citando algunos párrafos íntegramente, en castellano, y a pie de página incluiremos el texto original. Hallaremos una visión de la concepción artística, poética más en concreto, que puede resultar desconcertante; podemos aceptar significados esotéricos, mensajes o alegorías, cifradas en los textos sagrados e incluso en cualquier obra clásica en prosa, pero no estamos habituados a contemplar muchas de las posibilidades hermenéuticas hipotéticas que puede encerrar un texto sagrado. Desde ya, al decir "texto sagrado" no nos referimos a los canónicos de las religiones monoteístas: texto sagrado es aquí cualquier libro que haya sido sagrado en algún lugar o en algún época -incluimos entonces a Homero, Virgilio y todas las creaciones concebidas con la forma del verso y la métrica musical y que describen una historia eterna y sagrada, mítica o legendaria.

Primeramente, León Hebreo nos introduce en la cuestión de los sentidos (sensi) y alegorías (allegorici), cuando leemos,

\footnotetext{
FILÓN. - Los poetas antiguos no pusieron en sus poemas una sola sino muchas intenciones, que llaman "sentidos" (sensi). En primer lugar, ponen como sentido literal, como corteza exterior, la historia de algunas personas o de sus hechos notables, dignos de recuerdo. Luego, en la misma ficción, como corteza más intrínseca y más cerca de la médula, el sentido moral, útil para la vida activa de los hombres, que aprueba los actos virtuosos y vitupera los vicios. Además de esto, bajo las mismas palabras, presuponen algún conocimiento verdadero de las cosas naturales o celestes, astrologales o teologales, y, alguna vez, los dos o, mejor dicho, los tres sentidos científicos (li tre sensi scientifichi) coexisten dentro de la misma fábula, como la médula del fruto dentro de sus cortezas. Estos sentidos medulares se denominan "alegorías" (allegorici). (Hebreo, 1986, p. 114)
}

En esta primera aproximación que el personaje de Filón en la obra nos brinda para introducirnos en lo que explayará mejor en los siguientes párrafos, ya nos revela algunos datos importantes para caracterizar estas "intenciones" (intenzioni):

- un sentido literal,

- un sentido moral,

- un sentido esotérico, concerniente a las cosas naturales o celestes, astrologales o teologales, o ambas

Acá entonces tendríamos la estructura constitutiva de la creación poética, pero observamos ya algunas particularidades: "sentido moral" no es aquí meramente "moraleja". Sentido moral significa un ejemplo biográfico de virtud: una vida ejemplar como camino de vida, una crónica de hábitos virtuosos ganados y fortalecidos; la actitud frente al goce y la calamidad, ante el fracaso y la buena fortuna; descensos y ascensos; fallidos, tentaciones y victorias sobre la adversidad; elevación laboriosa y superación. La moraleja -y lo mismo le cabe a las obras motivadas por el "moralismo social" - es un sentido muy superficial y no 
corresponde con el "sentido moral" en que el creían los poetas antiguos. La moral de la que acá se nos habla no es una apelación a la bondad, la caridad, la honestidad, la castidad o la sensibilidad social, sino a un modo o filosofía ética y virtuosa de vida en el sentido aristotélico de estas dos palabras.

Después se menciona un sentido esotérico: se usan cuatro términos ("cosas naturales", "celestes", "astrologales" y "teologales") que no resulta fácil comprender a qué se está refiriendo y qué no son sinónimos ni intercambiables; cada una de estas palabras significa algo distinto y específico.

El primer caso, el de las cosas naturales, significa que la biología y la química siempre se mantuvieron en secreto, y eran reveladas de manera iniciática: Diotima revela los secretos biológicos (scientifichi) del amor entre los seres y la conservación de las especies a sus discípulos, u "oyentes" - que enseguida veremos qué significa esto. Es decir que se trata de las ciencias de la naturaleza y de sus secretos, desde la biología hasta la química y alquimia.

Luego refiere a las cosas celestes: éstas no son secretos místicos o divinos, sino secretos científicos, relativos a las ciencias de la atmósfera, la meteorología y algunos conocimientos extra-matemáticos relativos a la astronomía, aunque también esto corresponde a los secretos de orden metafísico. Recordemos el escándalo y las persecuciones que generó en la antigua Grecia la divulgación de las ciencias naturales y más concretamente de la meteorología, lo que obligó a que se escribieran obras como Las nubes de comediantes mediocres y de dudosa honestidad intelectual como Aristófanes para atacar y desprestigiar a estos conocimientos y así el pueblo se alejara un poco de ellos o no les diera credibilidad, ya que este saber científico ponía en crisis muchas creencias religiosas populares respecto a los rayos y relámpagos y las lluvias, atribuidos a designios divinos dadivosos o iracundos. A tal punto que Plutarco, en la Vida de Pericles, relata una anécdota en la que Anaxágoras causó un gran revuelo al explicar científicamente que un animal con un solo cuerno que había aparecido no era un prodigio o señal divina sino una obturación circulatoria en el cráneo desde su nacimiento que había impedido que el otro cuerno se desarrollase, a lo cual el célebre y elegante historiador, biógrafo, iniciado y sacerdote trató de improvisar una interesante explicación conciliadora entre la filosofía natural y el designio divino.

Para reforzar un poco el sentido científico del recurso críptico alegórico, recordemos, tan sólo al pasar, que los textos sagrados hindúes están repletos de alegorías para recubrir versículos donde se describen conocimientos o técnicas científicas, como por ejemplo en el shivaísmo tántrico, donde es común hallar tratados de ciencia respiratoria (pranayama) en un lenguaje alegórico, donde se convierte en una deidad alegórica a un canal energéticorespiratorio, o en una diosa a un centro psíquico-fisiológico de confluencia de energía (chakra); cascadas, cuevas, nupcias, portales, para describir conocimientos técnicos relativos a la canalización de la energía mediante la ciencia de la respiración:

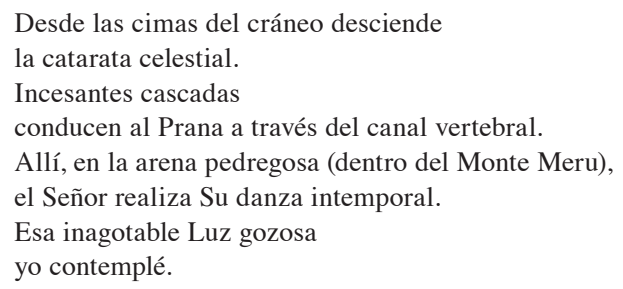

Ella es la doncella de los Vedas,

Ella pertenece al terreno astral del cráneo. 


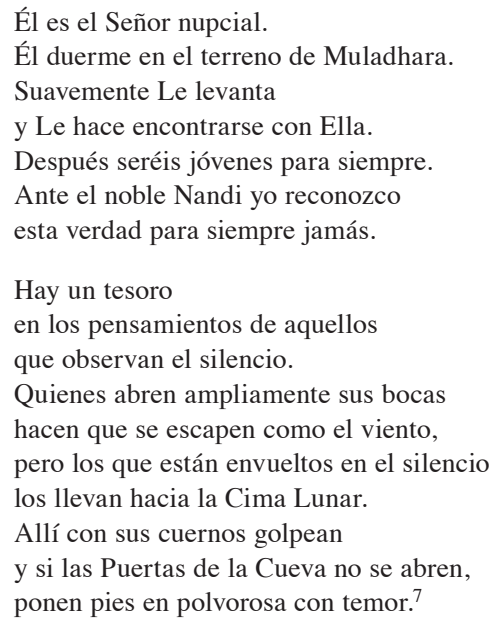

Los otros dos sentidos esotéricos son el astrologal y el teologal. León Hebreo pareciera encontrar algo problemático en esta categorización, porque evidentemente es posible que se confundieran - o no: es sólo una suposición. Ya que lo divino tiene su lugar en las jerarquías astrales, es decir: ¡jerarquías y esferas divinas! $!^{8}$ Presumo que, según el contexto esotérico, puede tratarse de una dimensión astrologal si éste es grecorromano o caldeo o egipcio hermético, o teologal si es, por ejemplo, angelología neoplatónica cristiana o musulmana. De cualquier manera, León Hebreo se encarga de ejemplificarlo en este pasaje,

\footnotetext{
FILÓN. - Seguramente crees, Sofía, que aquellos autores antiguos quisieron dedicar la mente tanto al artificio del significado de las cosas de las ciencias como al verdadero conocimiento de ellas. Te daré un ejemplo: Perseo, hijo de Júpiter (según ficción poética), mató a Gorgona, y, una vez vencedor, voló al éter, que es lo más alto del cielo. El sentido histórico es que Perseo, hijo de Júpiter, por participar de las virtudes de este último, o por descender de uno de aquellos reyes de Creta o de Atenas o de Arcadia, que se llamaron Júpiter, mató a Gorgona, tirana en la tierra, porque Gorgona significa, en griego, tierra; por haber sido virtuoso, los hombres le exaltaron hasta el cielo. También significa que Perseo (moralmente hablando, el hombre prudente), hijo de Júpiter, poseedor de las virtudes de éste, al matar al vicio bajo y terrenal, personificado por Gorgona, subió al cielo de la virtud. En sentido alegórico indica, primero, que la mente humana, hija de Júpiter, al matar y vencer la terrenidad de la naturaleza gorgónica, llegó a comprender las cosas celestes, elevadas y eternas, especulación en la cual consiste la perfección humana. Esta alegoría es natural, porque el hombre pertenece a las cosas naturales. Pero el mito encierra otra alegoría celeste; la naturaleza celeste, hija de Júpiter, dio origen, con su continuo movimiento, a la mortalidad y corrupción de los cuerpos inferiores terrestres; esta naturaleza celeste, vencedora de las cosas corruptibles, se separó de la mortalidad de aquéllas, voló hacia lo alto y se hizo inmortal. Encierra, además, una tercera alegoría teologal: la naturaleza angélica, que es hija de Júpiter, sumo dios, creador de todas las cosas, al matar y apartar de sí misma la corporalidad y la materia terrenal, personificada por Gorgona, subió al cielo, porque las inteligencias ajenas al cuerpo y materia son las que mueven perpetuamente las esferas celestes. (Hebreo, 1986, p. 115)
}

Aquí advertimos otra distinción que anteriormente no percibimos, aunque seguramente ya estaba implícita: una alegoría natural, "porque el hombre pertenece a las cosas naturales". Esto abre la posibilidad de que "las cosas naturales" puedan corresponderse con alegorías metafísicas respectivas a la ciencia del alma humana, es decir, psicológicas en el sentido aristotélico y escolástico de la palabra (el aspecto ingenito, o sea, lo recibido por naturaleza, la luz igual o inferior a lo humano); mientras que las "celestes" serían las que tienen que ver con el aspecto propiamente superior al psicológico, o "supralunar", si se prefiere (la luz superior a lo humano, el aspecto infuso, infundido por el Cielo). ${ }^{9}$ Pero tal es la fuerza, y tan larga tradición 
tiene, la costumbre de conservar de modo vedado, arcano, secreto, los conocimientos científicos de la alquimia, la química y la biología, que nos rehusamos a descartarlo, y tal vez debamos, en este sentido, contemplar un espectro de sentidos mucho más amplio: "natural”, alegóricamente hablando, sería todo lo concerniente a la biología, a la química, a la mineralogía, a la alquimia, a la medicina y a la psicología. Y, lo "celeste", serían los planos y esferas superiores.

Tenemos entonces un cuadro bastante claro y detallado de los niveles alegóricos en la composición poética. Respecto a los otros dos sentidos alegóricos esotéricos, el astrologal y el teologal, cabe una advertencia: de ninguna manera estos significados pueden reducirse solamente a alegorías "astronómicas", desprovistas de un significado metafísico más profundo. Es lo que ocurre con los arqueólogos que investigan los monumentos de Perú y América Central, o en el estudio que hace D. Ulansey sobre el mitraísmo, donde pareciera haber captado de forma sorprendente una complejísima estructura astronómica en toda su simbología, pero que sin embargo no vemos que nos ofrezca ningún significado más allá de lo puramente astronómico. ${ }^{10}$

Todo lo que escribe León Hebreo sobre los sentidos y alegorías, y sus diferentes niveles, y la caracterización que hace de cada uno de ellos, se sustenta con tan sólo remitirnos a las obras exegéticas que hace Servio de la Eneida - jamás traducidas al castellano- o que hace Porfirio de la Odisea.

\section{Los cuatro fundamentos de la creación poética}

A continuación, León Hebreo da una explicación de los fundamentos de la creación poética, y más concretamente: qué es lo que le da su fundamento y su razón de ser a la estructura métrica (al verso) y a los mitos e historias. Como veremos poco más adelante, esto evidencia un problema que debió suscitarse en el seno espiritual de los renacentistas, y es el dilema de optar por el verso o por la prosa, por la inclusión de mitos y alegorías o mantener la austeridad del tratado, a la hora de concebir una obra. Los tiempos medievales, sobre todo escolásticos, se caracterizaron por extensos tratados, arduos en complejidad, con estructuras metódicas expositivas asfixiantes que por momentos hacía imposible una lectura fluida, con un impecable y admirable orden intelectual pero gélidos, fríamente despojados de versos y alegorías y de cualquier tentativa de introducir belleza: frente a eso, los renacentistas optaron por... el diálogo, siguiendo una tradición que se remonta a Platón pero también a las escrituras sagradas del hermetismo. Así es que esta cuestión debió ser discutida y meditada en aquellos tiempos, y en aquellos círculos artísticos, espirituales y esotéricos de Europa.

Citamos, ahora, in extenso, el pasaje en el que se enumeran y explican las causas de la arcanización de los conocimientos en la creación poética y el recurso de la estructura métrica, el verso, la fábula y el mito:

SOFÍA. - Cosa admirable es conseguir encerrar en las pocas palabras necesarias para referir un hecho histórico, tantos sentidos de verdadera ciencia, cada uno más elevado que otro. Pero, por favor, dime, ¿por qué no dieron a conocer más libremente sus ideas?

FILÓN. - Quisieron decir estas cosas con tanta habilidad y brevedad por muchas causas. La primera, porque creían que resultaba odioso a la naturaleza y a la divinidad manifestar sus maravillosos secretos a cualquier persona; y en esto ciertamente tuvieron razón, porque divulgar demasiado la ciencia verdadera y profunda es dar alas a los inaptos, en la mente de los cuales esta ciencia se gasta y corrompe, como ocurre al buen vino en ruin vaso. Esta corrupción procede de divulgar demasiado las cosas científicas. En nuestra época se ha hecho tan contagiosa por el mucho hablar de los modernos, que apenas si es posible 
hallar vino intelectual que se pueda beber, que no esté agriado; pero en los tiempos antiguos, los secretos del conocimiento intelectual se incluían bajo las cortezas de las fábulas con grandísima habilidad, a fin de que no pudiera penetrar en su interior sino el ingenio apto para comprender las cosas divinas e intelectuales, la mente conservadora de las verdaderas ciencias, y no la que las puede corromper. [...] Lo hicieron, además, por otras cuatro causas. Una de ellas, la segunda, por buscar la brevedad, por encerrar en pocas palabras muchas sentencias, brevedad que es muy útil para conservar las cosas en la memoria, sobre todo por estar pensada de tal manera que, al recordar un hecho histórico, se puedan recordar todos los sentidos doctrinales incluidos en aquél, bajo las palabras. Tercera, por mezclar lo histórico y lo fabuloso, que deleita, con lo verdaderamente intelectual, lo fácil con lo difícil, a fin de que, al estar alimentada la fragilidad humana con el placer y la facilidad de la fábula, se colase de rondón en la mente la verdad de la ciencia, al igual que se suele iniciar a los niños en las cosas disciplinares y virtuosas, empezando por las más fáciles, máxime porque pueden estar juntas, unas en la corteza y otras en la médula, como se hallan en las ficciones poéticas. La cuarta causa, conservar las cosas intelectuales, para que no varíen con el correr del tiempo en las diversas mentes de los hombres, para que, al poner estas sentencias bajo tales historias, no se puedan apartar de los términos de aquéllas. Aun más, para conservarlas mejor han expresado la historia en versos medidos y cuidados, a fin de que no se pudieran corromper fácilmente, ya que la medida no puede sufrir el vicio, por lo que ni la disposición de los ingenios ni las incorrecciones de los escritores pueden adulterar con facilidad las ciencias. La última y principal causa es para que con un mismo alimento pudiesen comer diversos invitados cosas de varios sabores: las mentes bajas solamente pueden tomar de los poemas la historia junto con el adorno del verso y su meolodía; las más elevadas comen, amén de esto, el sentido moral; y otras, aún más elevadas, pueden comer, además de todo lo anterior, el alimento astrologal y teologal. Añádese a esto otra finalidad: dado que estos poemas pueden servir así de alimento común a toda clase de hombres, se logra perpetuar los hechos en la mente de la multitud, ya que las cosas muy difíciles pocos son los que las pueden gustar, y la memoria de unos pocos puede borrarse muy pronto, al sobrevenir una época que aparte a los hombre de la doctrina, según hemos visto ha ocurrido en algunas naciones y religiones, como los griegos y los árabes, que, habiendo sido muy sabios, han perdido por completo la ciencia. Y así sucedió en Italia en la época de los godos, aunque luego renació lo poco que ahora tenemos. El remedio para evitar este peligro consiste en ocultar las ciencias bajo poemas fabulosos e históricos, que, gracias al placer que producen y a la suavidad del verso, andan y se conservan en boca de pueblo, de hombres, de mujeres, de niños. (Hebreo, 1986, pp. 115-116)

La metáfora del vino y el vaso podría también tener alguna inspiración en la cábala, en la que la palabra secreto $(\mathrm{sod})$ tiene el mismo valor numérico que la palabra vino (iaín). León Hebreo se asume, personificado en Filón, como un italiano renacentista que observa el empobrecimiento sapiencial y científico de los griegos y los árabes como consecuencia de la llegada de una época que apartó a los hombres de la doctrina (una età que facesse deviare gli uomini de la dottrina). Acá está uno de los fundamentos más fuertes de todo esoterismo: lo sagrado se rebaja, lo elevado sufre una degradación; las palabras de los sabios en boca de los ineptos se tornan huecas y superficiales, y en boca de los mediocres, se opacan y se empobrecen. Ése sería el genuino sentido del concepto de profanación. ¿Por qué, entonces, se corrompen? Porque fuera de su ámbito de sacralidad, se envilecen; se tornan objeto de tergiversaciones, de análisis triviales, del comercio institucional del docente que cumple un programa de estudios y del estudiante que busca la aprobación de un examen, en suma: se deslucen, se rebajan, se empobrecen... como un gran sabio -imaginemos por un momento un Heráclito, un Séneca - que tuviera cursar la escuela secundaria - o acaso terciaria - rodeado de adolescentes insípidos y profesores mediocres y malhumorados, o como una obra maestra de la creación poética repartida en una cancha de fútbol.

Pero hay otro elemento, que no se menciona, y en el que creemos que vale la pena detenerse muy seriamente y con suma atención: ¿el riesgo de que se conozcan los secretos, y el motivo por el que se los resguarda, es realmente que caigan en las manos y en las mentes de los ineptos, o más bien, el verdadero peligro, es que caigan bajo el poder y el conocimiento de los adversarios, de los invasores, de las religiones depredadoras, de los brujos o del oscurantismo? 
Tenemos una concepción del arte como reservorio experiencias, hallazgos y creaciones del espíritu humano, como ciudadela amurallada en la que habitan las enseñanzas secretas, las ciencias ocultas, las claves de los enigmas, la más arcana simbología donde nadie sospecha, la verdad olvidada. Tenemos asimismo diferentes plataformas para diferentes niveles de entendimiento; una escala de grados de comprensión para que todos, desde los sabios y los iniciados hasta los más pequeños, puedan participar y beber de la fuente oculta, en las grutas que dan acceso a la sagrada memoria, a las portentosas revelaciones, a la eterna y esplendorosa sabiduría y a la fresca y cristalina reminiscencia del alma.

\title{
5. La creación poética en Platón y Aristóteles: secreto y divulgación
}

\author{
... i libri suoi erano editi e non editi \\ (“...sus libros estaban editados pero no estaban editados”)
}

Los más grandiosos y divinos referentes espirituales de la civilización occidental, Platón y Aristóteles, debían ser referentes, para los sabios del Renacimiento, desde luego también en lo que concierne a la creación poética. Volver a las fuentes planteaba también este dilema: cómo concebir el arte, cómo conservar el conocimiento, qué mantener oculto y qué revelar al mundo. El Renacimiento, para superar la escolástica y el racionalismo medieval, se aleja un poco de Aristóteles - o por lo menos del aristotelismo-, pero al mismo tiempo, para afirmar su espíritu humanista, no podía pretender un regreso a los tiempos muy arcaicos, como los tiempos homéricos. Y así, el equilibrio armonioso que guía sus aspiraciones más excelsas lo terminan encontrando estos sabios en Platón, el divino.

\begin{abstract}
SOFÍA. - Me agradan todas estas causas de las ficciones poéticas. Pero, dime: Platón y Aristóteles, príncipe de los filósofos, ¿por qué uno de ellos no quiso (aunque utilizó la fábula) valerse del verso, sino sólo del a prosa, y el otro no utilizó el verso ni la fábula, sino la oración lógica?

FILÓN. - Jamás quebrantan las leyes los pequeños; sólo lo hacen los grandes. El divino Platón, queriendo ampliar la difusión de la ciencia, le quitó una cerradura, la del verso; pero no la otra, la fábula. De manera que fue el primero que rompió parte de la ley de la conservación de la ciencia, pero la dejó cerrada con el estilo fabuloso, que es suficiente para conservarla. Aristóteles, más audaz y amigo de ampliarla, con nuevo y propio estilo en el decir, quiso también quitar la cerradura de la fábula y romper por completo la ley de la conservación, y habló en estilo científico, en prosa, de las cosas filosóficas. Cierto es que desplegó una habilidad tan grande en su decir, tan breve, comprensible y de tan hondo significado, que bastó éste para conservar la ciencia, sin recurrir así ni al verso ni a la fábula, hasta el extremo de que, al contestar a Alejandro el Macedonio, su discípulo, el cual le había escrito que se maravillaba de que hubiese puesto de manifiesto los libros tan secretos de la filosofía, él le respondió que sus libros estaban editados y eran inéditos: editados sólo para aquellos que de él lo oyeron. De estas palabras podrás darte cuenta, Sofía, de la dificultad y del artificio que encierra el lenguaje de Aristóteles. (Hebreo, 1986, p. 117)
\end{abstract}

No nos dice León Hebreo, en este interesante pasaje, qué pudo motivar a Platón a quebrantar esa ley de conservación de la ciencia. Nosotros tenemos una hipótesis: debía abrirse al mismo nivel de divulgación pública de sus adversarios, que no hablaban con secretos sino más abiertamente de las cosas filosóficas. Hay algo más, y es el hecho de que no fue Platón el inventor y difusor de este nuevo género: el del diálogo, que ya circulaba entre los filósofos hoy llamados "sofistas" y "socráticos". No deja, sin embargo, de ser un enigma qué es lo que motiva este "giro" de lo arcano a la difusión, inclusive más enigmática considerando que esta difusión, como la de Aristóteles, tan abierta y sin misterios como parece, sigue encerrando secretos y aspectos esotéricamente vedados. Los libros sólo podrían comprenderlos "los que oyeron", 
es decir, los que aprendieron con el maestro, los que recibieron enseñanza de él. Los libros entonces circularían como apuntes, como notas, como conservación ordenada y por escrito de las enseñanzas. ¿Pero es suficiente? ¿sólo con la mera finalidad de plasmar por escrito unos apuntes de clase es que llegan hasta nosotros las obras de Aristóteles? Creemos que no: el corpus aristotélico tiene la misma finalidad de conservación de ciencias y doctrinas, pero como segunda finalidad se propone serlo de una forma más explícita, menos oscura, que principalmente disipe toda posibilidad de malos entendidos y, por encima de todo, de malversación de las enseñanzas; Aristóteles sabe que la oscuridad total en una enseñanza hace que si se ve interrumpida su trasmisión directa la doctrina se pierda para siempre, pero sabe además que una divulgación confusa y renuente en claridad puede ser agua que cada cual se lleve para su molino. Los tiempos cambiaron, y el mal menor es difundir las enseñanzas de la manera más clara posible; en última instancia, solamente unos pocos son los aptos para cosechar y obtener las inferencias, las verdades y las consecuencias implícitas que se deducen en estas enseñanzas cuando se las estudia con atención, no descifrando nada secreto, sin buscar ningún mensaje oculto y cifrado: sólo meditando atenta y detenidamente lo que está escrito y las implicancias inesperadas y desconcertantes que tiene y todo lo que de ello se extrae. Lo secreto ya no se oculta por debajo, sino latente en todo lo que se reconstruye a partir de las premisas.

\footnotetext{
FILÓN. - Él llama oyente suyo a aquel cuyo entendimiento comprende y filosofa según lo hacía su entendimiento, sea cual sea la época y el lugar en que viva. Quiere decir que sus palabras escritas no convierten en filósofos todos los hombres, sino solamente a aquellos cuya mente es apta para el conocimiento filosófico, como era la suya. Éste le entenderá; los demás, no, como ocurre con aquella filosofía cuyo sentido está oculto bajo una ficción poética.
}

SOFÍA. - Según esto, Aristóteles no hizo mal en eliminar la dificultad del verso y de la fábula, ya que encerró la doctrina bajo una cerradura suficiente para conservar la ciencia en las mentes claras.

FILÓN. - No hizo mal, porque puso remedio, gracias a la grandeza de su genio; pero dio alas a otros carentes de su genio para escribir filosofía en prosa suelta. Y así, de una manifestación en otra, llegando a mentes inaptas, ha sido causa de que se haya falsificado, corrompido y arruinado. (Hebreo, 1986, p. 117)

\section{La desintegración de las artes}

En los pasajes que hemos transcripto y analizado puede verse la progresiva desintegración de las artes. Si la tradición no miente, géneros como el diálogo o la novela son desprendimientos de un género originario, que era la creación poética: estructura métrica e historia mítica. El tratado y el soneto, serían también una forma degradada de un género arquetípico primigenio, mientras que el ensayo - en el sentido moderno, en el sentido de Montaigne- y el verso libre, serían todavía más bajos en grado que aquéllos.

Hoy en día, para que algo sea poesía le basta cumplir el requisito de estar escrito gráficamente en forma de verso; no hay a veces diferencia entre una oración partida, en grupos de palabra, o palabras sueltas, una debajo de la otra, y un poema. El ensayo, por su parte, en muchos casos ya no solamente no encierra ningún significado más allá de la simple lectura, sino que a veces ya ni siquiera alcanza a expresar ordenada y coherentemente lo que se propuso expresar y trasmitir.

El proceso es claramente de disgregación, pero no debe ser un motivo de lamentación y anhelo por lo pasado: en todas las épocas el arte y la sabiduría florecen de una manera de otra; en otro estudio hemos observado que la arcanización en la creación artística se ha desplazado a otras artes, como el arte cinematográfico: películas como Papillon (1979), The Truman Show 
(2000), Hardcore (1979), Birth (2004) o series como X-Files encierran poderosos simbolismos y alegorías, insospechados e inadvertidos.

Lejos de la nostalgia, y para evitar un pesimismo quejumbroso, y por lo demás inútil, sin sentido, lo único que consideramos de importancia indicar es que lo que parece obvio a los ojos de la comprensión es que hemos perdido los arquetipos y en lugar de ello tenemos modas; carecemos de criterios estéticos porque prevalece el relativismo; despreciamos como artistas adquirir una formación sólida en las técnicas y su destreza; olvidamos la preferencia por la autoridad de los clásicos y en cambio ponderamos los veredictos del galardón y de la crítica literaria; no tenemos gusto ni afán por lo arcano y por lo secreto, y en lugar de ello nos seduce lo confuso y lo ininteligible; en otras palabras, dejo una pregunta: ¿nos hemos vuelto insensibles a los secretos, a los misterios y al sentido de la majestad de lo sagrado?

\section{Notas}

1. Moreyra, C. A. (1996). La Contrarreforma jesuítica y el gran arte críptico. Córdoba: El Copista.

2. Neumeister, S. (1996). "Visualización verbal en El discreto de Gracián”. Por I. Arellano, M. C. Pinillos, F. Serralta y M. Vitse. (Eds.). Studia Aurea (Actas del III Congreso de la AISO, Toulouse, 1993). Toulouse-Pamplona: GRISO-LEMSO.

3. Hebreo, L. (1986). Diálogos de amor. Madrid: Técnos.

4. Idel, M. (2002). Absorbing perfections: Kabbalah and interpretation. New Haven: Yale U Press.

5. "In a famous passage on the nature of the mystery experience, Aristotle distinguished between mystery and philosophy by describing those who had undergone the mystery rite as having been affected and suffering rather than as learning. This experiential aspect of being initiated into mysteries is quintessential for these religions, even if one may argue that learning quite often involves some forms of experience. Thus, though I would refrain from overemphasizing radical differences between extensive corpora, I would claim that in ancient Jewish esotericism-with the notable exception of the Therapaeuts, Philo of Alexandria, and related Alexandrian Jewish phenomena where the importance of contemplation is more evident-the experiential element was combined much more with the idea of learning than it was in the Greek mystery religion ambiance. Because of the loaded meaning of the term "mystery", as referring mainly to an experiential event and less, if at all, to learning, I have decided not to use this term in the following discussions and to prefer such terms as "secret" and "arcanization". The latter term can be understood as referring to both conscious and unconscious effots to introduce secrets into the canonical texts, as the result of either a systemic development or a crisical situation." (Idel, 2002, op. cit., p. 167).

6. Scholem, G. (1993). Las grandes tendencias de la mística judía. Buenos Aires: Fondo de Cultura Económica.

7. Estos versículos (sutras 589, 590 y 593) corresponden a una versión castellana, traducción anónima o desconocida, del texto tántrico de yoga Tirumandiram, procedente a su vez de una versión inglesa: Thirumoolar, S. (1993). Thirumantiram. A classic of Yoga and Tantra. (B. Natarajan, tr.). Montreal: Babaji’s Kriya Yoga. [En castellano disponible online en: http://www.libroesoterico.com].

8. Inevitable mencionar los estudios de Franz Cumont, como Astrología y religión en el mundo grecorromano (Barcelona: Edicomunicación, 1989), y otras, infelizmente nunca traducidas a nuestra lengua, entre ellas Les mystèries de Mithra, Les Syriens en Espagne et les Adonies à Seville o L'Égypte des Astrologues.

9. $\quad$ Ficino, op. cit., IV, II. Una versión traduce ingenito e infuso por (luz) natural y (luz) sobrenatural (M. Lamberti \& J. L. Bernal, trs.), Sobre el amor. Comentarios al Banquete de Platón, UNAM, México, 1994. La idea de Ficino sería que el homo recibe una luz inherente a su misma naturaleza y otra infundida. La tesis es irreductiblemente dualista, aún cuando sitúa estas dos luces como ya existentes en una dimensión originaria donde estaban inseparablemente unidas: ¿también allí, cuando estaba integradas, eran una luz ingénita y una luz infundida? ¿o eran una sola y única luz, y la razón, el instinto, 
el intelecto, el espíritu y la luz divina eran una y la misma cosa sin diferencias - y la redención de la condición humana llega cuando se ha alcanzado en el hombre la sublimación divina de todas estas distinciones?

10. Ulansey, D. (1991). The Origins of Mitharic Mysteries. Oxford: Oxford U Press.

\section{Bibliografía}

Abravanel, J./ Hebreo, L. (1986). Diálogos de amor. Madrid: Técnos, Madrid.

Culianu, I. (2007). Eros y magia en el Renacimiento. Madrid: Siruela.

Gómez de Liaño, I. (2003). El diagrama del primer evangelio. Madrid: Siruela.

Cumont,F.(1989).Astrología y religiónen elmundogrecorromano.Barcelona:Edicomunicación.

Cumont, F. (2008). The Mysteries of Mithra. Nueva York: Cosimo.

Ficino, M. (1994). Sobre el amor. Comentarios al Banquete de Platón. México: UNAM.

Huidobro, V. (1989). Obra selecta. Caracas: Fundación Biblioteca Ayacucho.

Idel, M. (2002). Absorbing perfections: Kabbalah and interpretation. New Haven: Yale U Press.

Mazzotti, J. A. (2009). Otros motivos para la «Traduzion»: el Inca Garcilaso, los «Diálogos de amor» y la tradición cabalística. http://www.cervantesvirtual.com/nd/ark:/59851/ bmcpr898 [Consulta 25 de mayo de 2016].

Moreyra, C. A. (1996). La Contrarreforma jesuítica y el gran arte críptico. Córdoba: El Copista.

Neumeister, S. (1996). “Visualización verbal en El discreto de Gracián”. Por I. Arellano, M. C. Pinillos, F. Serralta y M. Vitse. (Eds.). Studia Aurea (Actas del III Congreso de la AISO, Toulouse, 1993). Toulouse-Pamplona: GRISO-LEMSO.

Scholem, G. (1993). Las grandes tendencias de la mística judía. Buenos Aires: Fondo de Cultura Económica.

Thirumoolar, S. (1993). Thirumantiram. A classic of Yoga and Tantra. (B. Natarajan, tr.). Montreal: Babaji's Kriya Yoga.

Ulansey, D. (1991). The Origins of Mitharic Mysteries. Oxford: Oxford U Press.

Zazo-Jiménez, E. (2011). La crítica platónica de la poesía como crítica de la tradición oral. Revista Tales. 4, 75-87. 
